\title{
Planktivorous feeding in calm and turbulent environments, with emphasis on copepods
}

\author{
Thomas Kiørboe ${ }^{1}$, Enric Saiz ${ }^{2}$ \\ ${ }^{1}$ Danish Institute for Fisheries and Marine Research, Charlottenlund Castle, DK-2920 Charlottenlund, Denmark \\ ${ }^{2}$ Institut de Ciències del Mar, CSIC, Passeig de Joan de Borbó s/n, E-08039 Barcelona, Spain
}

\begin{abstract}
Turbulence may enhance contact rates between planktonic predators and their prey. We formulate simple and general models of prey encounter rates, taking into account the behaviours and motility patterns of both prey and predator as well as turbulent fluid motion. Using these models we determine the levels of turbulence (as dissipation rate) at which ambient fluid motion is important in enhancing prey encounter rates for various types of predators (e.g. ambush and cruise predators, suspension feeders). Generally, turbulence has the largest effect on prey encounters for predators with low motility and long reaction distances. Also, turbulence is most important for meso-sized ( $\mathrm{mm}$ to $\mathrm{cm}$ ) predators and insignificant for smaller and larger predators. The effect of turbulence on copepods is specifically examined. For copepods that establish feeding currents, turbulence is of minor importance; for ambush feeding copepods, such as Acartidae and many cyclopoids, turbulence has a dominant influence on prey encounter rates. The effect on cruising predators is intermediate. Application of the models to situations examined experimentally demonstrates a high predictive performance. Finally we explore and model the potentially negative effects of turbulence on copepod feeding currents, prey perception and capture success. At typical and even high turbulent intensities, none of these is significantly affected.
\end{abstract}

KEY WORDS: Turbulence $\cdot$ Encounter rate $\cdot$ Zooplankton $\cdot$ Feeding $\cdot$ Predation

\section{INTRODUCTION}

Rothschild \& Osborn (1988) suggested that microscale turbulence increases planktonic predator-prey contact rates because turbulent fluid motion increases the velocity difference between predators and their prey. Although the mathematical treatment was not easily accessible, the concept was intuitively appealing and, due to the potentially significant effects on plankton trophodynamics, the Rothschild \& Osborn theory has since received considerable attention (e.g. Mann \& Lazier 1991, Kiørboe 1993). Rothschild \& Osborn themselves demonstrated only small effects of turbulence an increase in contact rates of a few up to $50 \%$ - but subsequent application to e.g. fish larvae has demonstrated a potentially substantial enhancement (up to a factor of 10) of predator-prey contact rates at realistic intensities of turbulence (e.g. MacKenzie \& Leggett 1991).

Rothschild \& Osborn (1988) assumed a simple and in many cases unrealistic behaviour of both prey and predator (linear swimming). Subsequent modeling exercises have incorporated 'random walk' types of behaviour. These latter attempts (Evans 1989, Yamazaki et al. 1991) were again purely theoretical, not applied to any real predators, and very difficult for the nonmathematician to understand, apply, and test. The effect of turbulence on encounter rates for predators and prey with other behavioural patterns ie.g. ambush predators and suspension feeders which generate feeding currents) has not been examined theoretically.

Despite a considerable amount of theoretical work (Rothschild \& Osborn 1988, Evans 1989, Granata \& Dickey 1991, Yamazaki et al. 1991), there are few studies that have attempted to actually examine the effects of turbulence on predator-prey encounter rates, and several of those are based on misinterpretations of the equations given by Rothschild \& Osborn (1988) ie.g. Sundby \& Fossum 1990, Davis et al. 1991, MacKenzie \& Leggett 1991, Kiørboe 1993). The relative scarcity of 
empirical evidence is partly due to the difficulties involved in setting up sound experimental systems for testing. However, we also ascribe it to the general inaccessibility of the theory.

In this study we derive simple equations from classical particle encounter theory that take different types of predator and prey behaviours into account, allowing us to examine the effect of turbulence. Our approach is somewhat similar to that of Rothschild \& Osborn (1988), but our results are more general. Emphasis is put on simplicity, intelligibility and applicability to allow and stimulate researchers to experimentally examine the effect of turbulence on planktivorous feeding rates. The model has been developed with copepods in mind, but the equations are generalized so that they apply to other planktivorous predators as well. We evaluate for what types of planktonic predators turbulence is likely to be of importance, and finally we apply the model to some real situations that have been examined experimentally.

\section{TURBULENCE AND FLUiD VELOCITIES}

Turbulence can be generated by wind, waves, currents, tides and other processes that add turbulent (kinetic) energy to the water column. Turbulence first appears as large-scale eddies that subsequently dissipate into smaller and smaller eddies. Although water motion is random, the eddies have a characteristic and universal size distribution. There is a minimum size of turbulent eddies, related to the so-called Kolmogorov

Táble 1. (a) Typical intensities of ocean turbulence (Granata \& Dickey 1991, MacKenzie \& Leggett 1991), and (b) average turbulent intensities in the upper $10 \mathrm{~m}$ generated by wind alone (calculated according to MacKenzie \& Leggett 1993) The equivalent Kolmogorov length scales $\left(L_{k}\right)$ and fluid shear rates are also shown

\begin{tabular}{lccc}
\multicolumn{4}{l}{ (a) Typical intensities } \\
Site & $\varepsilon\left(\mathrm{cm}^{2} \mathrm{~s}^{-3}\right)$ & $L_{\mathrm{k}}(\mathrm{cm})$ & Shear $\left(\mathrm{s}^{-1}\right)$ \\
\hline Open ocean & $10^{-6}$ to $10^{-2}$ & 1.00 to 0.10 & 0.01 to 1.00 \\
Shelf & $10^{-3}$ to $10^{-2}$ & 0.18 to 0.10 & 0.32 to 1.00 \\
Coastal zone & $10^{-3}$ to $10^{\circ}$ & 0.18 to 0.03 & 1.00 to 10.00 \\
Tidal front & $10^{-1}$ & 0.06 & 3.16
\end{tabular}

(b) Intensities in upper $10 \mathrm{~m}$ due to wind

\begin{tabular}{cccc}
$\begin{array}{c}\text { Wind speed } \\
\left(\mathrm{m} \mathrm{s}^{-1}\right)\end{array}$ & $\begin{array}{c}\text { Avg. } \varepsilon \text { in upper } \\
10 \mathrm{~m}\left(\mathrm{~cm}^{2} \mathrm{~s}^{-3}\right)\end{array}$ & $L_{\mathrm{k}}(\mathrm{cm})$ & Shear $\left(\mathrm{s}^{-1}\right)$ \\
\hline 5 & $1.7 \times 10^{-3}$ & 0.16 & \\
10 & $1.5 \times 10^{-2}$ & 0.09 & 0.4 \\
15 & $4.9 \times 10^{-2}$ & 0.07 & 2.2 \\
20 & $8.4 \times 10^{-2}$ & 0.06 & 2.9
\end{tabular}

length scale, where fluid viscosity dominates and below which all turbulent energy dissipates as heat and water motion can be characterized as laminar shear. The intensity of turbulence can be characterized by the energy dissipation rate, $\varepsilon\left(\mathrm{W} \mathrm{kg}{ }^{-1}=10^{-4} \mathrm{~cm}^{2}\right.$ $\mathrm{s}^{-3}$, and the fluid velocities that are generated by turbulence are directly related to the energy dissipation rate (see below). The Kolmogorov length scale, $L_{k_{1}}$ depends on the energy dissipation rate,

$$
L_{\mathrm{k}}=\left(\frac{\mathrm{v}^{3}}{\varepsilon}\right)^{0.25}
$$

where $v$ is the kinematic viscosity (ca $10^{-2} \mathrm{~cm}^{2} \mathrm{~s}^{-1}$ ). Since typical dissipation rates in the ocean are $10^{\circ}>\varepsilon>$ $10^{-6} \mathrm{~cm}^{2} \mathrm{~s}^{-3}$ (Granata \& Dickey 1991, MacKenzie \& Leggett 1991), the Kolmogorov length scale is typically less than $1 \mathrm{~cm}$ and larger than $0.03 \mathrm{~cm}$ (Table 1 ). Because water motion differs below and above the Kolmogorov length scale, the equations relating turbulenl velocities to $\varepsilon$ are different, and the particle encounter rates due to turbulence also differ. The equations relating the velocity difference $(\omega)$ between 2 points separated by a distance $d$ to dissipation rates are:

for $d<$ Kolmogorov length scale (Jackson \& Lochman 1993)

$$
\omega=0.42 d\left(\frac{\varepsilon}{v}\right)^{0.5}
$$

and for $d>$ Kolmogorov length scale (Delichatsios \& Probstein 1975)

$$
\omega=1.37(\varepsilon d)^{1 / 3}
$$

where $(\varepsilon / v)^{0.5}$ is the sub-Kolmogorov scale fluid shear rate $\left(\gamma, s^{-1}\right)$.

Applications of the Rothschild \& Osborn equations to fish larvae and copepods have hitherto used $d>$ Kolmogorov length scale theory (e.g. Sundby \& Fossum 1990, MacKenzie \& Leggett 1991, Saiz 1994), even though these organisms may experience a $d<$ Kolmogorov scale environment (i.e. having visual or perceptive distances that are below the Kolmogorov scale). However, Hill et al. (1992) have recently shown experimentally that $d>L_{\mathrm{k}}$ equations are valid well below the Kolmogorov scale. For smaller planktivorous organisms like ciliates, however, $d<L_{\mathrm{k}}$ equations should be applied.

\section{PARTICLE ENCOUNTER THEORY}

Suspended particles, or predators and prey, encounter each other only if they move at different velocities relative to one another, Various processes may generate such velocity differences; the particles 
may sink at different velocities, they may swim (in different patterns), they may generate feeding currents, or fluid motion may bring the particles into contact. It is a classical physical problem to derive expressions to calculate particle encounter rates due to various processes. Consider 2 types of spherical 'particles' (prey and the perceptive sphere of the predator) occurring at concentrations $C_{1}$ and $C_{2}$ (ind $\mathrm{cm}^{-3}$ ). The particle encounter rate, $E$ (encounters $\mathrm{cm}^{-3} \mathrm{~s}^{-1}$ ), is given by:

$$
E=\beta C_{1} C_{2}
$$

where $\beta$ is the encounter-rate coefficient, or kernel, and has units of $\mathrm{cm}^{3} \mathrm{~s}^{-1}$. The encounter rate per predator, e, equal to the ingestion rate if all encountered prey particles are captured, is:

$$
e=\frac{E}{C_{1}}=\beta C_{2}
$$

It can be seen that $\beta$ is equivalent to what is usually termed the 'clearance rate' or 'search volume rate' in the biological literature (provided that capture efficiency is $100 \%$ ).

Mathematical expressions for encounter rate kernels abound in the literature, and differ for the different 'particle' behaviours and physical processes. As various processes bring particles together, various expressions for $\beta$ may accordingly be derived. The kernel, $\beta$, is normally assumed to be the sum of the kernels for the individual relevant processes (O'Melia \& Tiller 1993), i.e. $\beta=\sum \beta_{i}$. This approximation simplifies the following considerations substantially. We shall distinguish between 2 types of kernels, those due to the behaviour of the organisms ( $\beta_{\text {behaviour }}$ ), and those due to water motion ( $\beta_{\text {turbulence }}$ ). We will ignore the kernel for Brownian motion, because it is insignificant for particles $>1 \mu \mathrm{m}$ (Berg 1983). We shall consider passive sinking as a behavioural component. The predator's encounter rate with prey in calm water is thus given by inserting $\beta_{\text {behaviour in Eq. (5), while the }}$ encounter rate in turbulent water is given by inserting $\beta_{\text {behaviour }}+\beta_{\text {turbulence. }}$. The latter, of course, requires that the behaviour of both predator and prey is unaffected by turbulent fluid motion. Although we will initially make this assumption, it will be discussed in further detail in a later section. We first examine the behavioural kernels.

\section{Behavioural kernel}

A simple conceptual example may illustrate the behavioural kernels. Consider a predator with a visual range (perceptive distance) $r_{1}$, swimming with velocity $v_{1}$ along a straight path while searching for immobile spherical prey particles with radius $r_{2}$. Per unit time the predator will encounter the prey organisms in the volume given by:

$$
\beta_{\text {behaviour }}=\pi\left(r_{1}+r_{2}\right)^{2} v_{1}
$$

which is then the kernel for this process. If the prey particles also move along straight lines in random directions, with velocity $v_{2}$, then the velocity difference between prey and predator increases and the kernel becomes (for $v_{1}>v_{2}$ ):

$$
\beta_{\text {behaviour }}=\pi\left(r_{1}+r_{2}\right)^{2}\left(\frac{v_{2}^{2}+3 v_{1}^{2}}{3 v_{1}}\right)
$$

While the first kernel is easy to understand, the latter is derived by more convoluted arguments (Gerritsen \& Strickler 1977).

Swimming along straight paths is an unrealistic assumption for many real prey and predators. The extreme alternative type of swimming behaviour is the 'random walk'. Many ciliates and bacteria, for example, have this type of behaviour: they swim short distances, and between swimming runs they tumble and continue swimming in a new, random direction. This motility pattern can be quantified as a 'diffusion' coefficient, $D\left(\mathrm{~cm}^{2} \mathrm{~s}^{-1}\right)$, which is given by (Berg 1983):

$$
D=\frac{v^{2} \tau}{3}
$$

where $v$ is the swimming velocity and $\tau$ is the time interval between tumbles. If the motility of both prey and predator can be characterized as a 'random walk', then the behavioural kernel for diffusion is (Jackson \& Lochmann 1993):

$$
\beta_{\text {behanour }}=4 \pi\left(D_{1}+D_{2}\right)\left(r_{1}+r_{2}\right)
$$

where $D_{1}$ and $D_{2}$ are the diffusion coefficients for predator and prey, respectively.

We next consider passive sinking. Some organisms do not swim actively, but remain passive in the water column, while slowly sinking (ambush predators). An example is the calanoid copepod Acartia tonsa preying upon ciliates, to be considered in further detail in a later section. If the prey has a similar behaviour to that of the predator then the kernel for differential sinking is:

$$
\beta_{\text {behaviour }}=\pi\left(r_{1}+r_{2}\right)^{2}\left|v_{1}-v_{2}\right|
$$

where $v$ now denotes the sinking rather than the swimming velocities.

Many suspension feeders (e.g. copepods) generate feeding currents. In essence, feeding currents make prey particles move relative to the predator. Although the predator may move forward due to the feeding current, the velocity difference can be expressed solely as the prey velocity relative to the predator. This velocity 


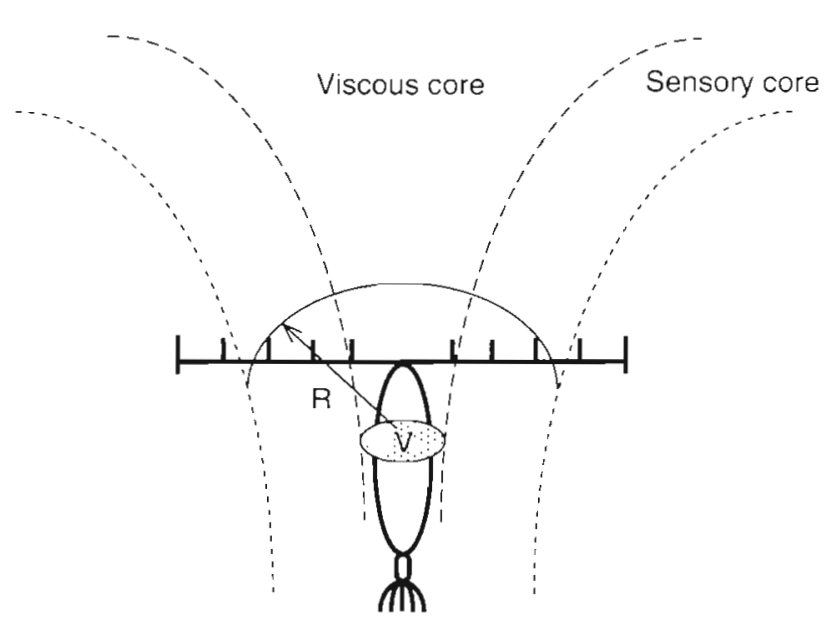

Fig. 1 Schematic drawing of the flow field generated by a suspension-feeding copepod. Only particles passing through the capture volume (V) can be collected. The feeding current drives water within the viscous core through the capiure volume. The reaction distance (arrow $\mathrm{R}$ ) is the distance at which particles can be sensed. Particles outside the viscous core but within the sensory core can be sensed and rerouted into the viscous core. (Modified from Strickler 1985)

is not constant since the feeding current (and the prey) accelerates as it approaches the predator. In the simplest situation where the predator cannot sense prey particles individually, the kernel for suspension feeding is:

$$
\beta_{\text {behaviour }}=\pi\left(r_{1}+r_{2}\right)^{2} v
$$

where $I_{1}$ is the radius of the capture volume (i.e. the volume swept by the copepod's food collecting appendages), $r_{2}$ is the prey radius, and $v$ is the velocity of the prey particle (relative to the predator) as the particle passes through the capture volume.

It has been shown that several copepod species can sense algal particles individually, likely by chemical cues, and are able to reroute particles from the 'sensory core' to the 'viscous core' (see Fig. 1; Strickler 1985, Paffenhöfer \& Stearns 1988). The same kernel applies here, but now the relevant $r_{1}$ is the perceptive (reaction) distance, and $v$ is the velocity of the prey particle (relative to the predator) in the feeding current at the point where it enters the perceptive field. Note that in this context the predator swimming velocity per se is irrelevant.

\section{Kernel due to turbulence}

The kernel for turbulence is:

$$
\beta_{\text {turbulence }}=\pi d^{2} \omega
$$

where $\omega$ is the turbulent velocity as defined above (Hill et al. 1992). Several authors have misinterpreted the equations of Rothschild \& Osborn (1988) and erroneously considered $d$ as the mean separation distance between predator and prey. However, the relevant velocity is that immediately before contact; i.e. $d=r_{1}+$ $I_{2}$ (Evans 1989). Inserting the expressions for turbulent velocity (Eqs. 2 and 3 ) and setting $v=10^{-2} \mathrm{~cm}^{2} \mathrm{~s}^{-1}$ yields:

for $d<$ Kolmogorov length scale

$$
\beta_{\text {turbulence }}=4.2 \pi \varepsilon^{0.5}\left(r_{1}+r_{2}\right)^{3}
$$

and for $d>$ Kolmogorov length scale

$$
\beta_{\text {turbulence }}=1.37 \pi \varepsilon^{1 / 3}\left(r_{1}+r_{2}\right)^{7 / 3}
$$

\section{SIGNIFICANCE OF TURBULENT FLUID MOTION FOR PREY ENCOUNTER}

To evaluate the potential significance of turbulence for enhancing prey encounter rates we need to compare the relative ruagninitudes of $\beta_{\text {behavour }}$ and $\beta_{\text {turbulence. }}$ If $\beta_{\text {turbulence }}>\beta_{\text {behaviour }}$ fluid motion dominates prey encounter. We here examine, for the behavioural types considered above, the relative importance of turbulence for prey encounter, in both below-and aboveKolmogorov length scale situations. For simplicity we will assume that the motility and radius of the prey are negligible (i.e. $v_{2}$ and $D_{2}=0, r_{2}=0$ ). This is a good approximation in many cases, because often prey velocities $\ll$ predator velocities and prey size $\ll$ predator reaction distance.

\section{Case 1: Straight swimming (cruising predator)}

Our evaluation criterion, $\beta_{\text {turbulence }}>\beta_{\text {behaviour }}$ becomes for $d<L_{k}$ situations (Eqs. $6 \& 13$ ):

$$
4.2 \pi \varepsilon^{0.5} r_{1}^{3}>\pi r_{1}^{2} v_{1}
$$

which reduces to:

$$
\varepsilon>0.057\left(\frac{v_{1}^{2}}{r_{1}^{2}}\right)
$$

Similarly, in the $d>L_{\mathrm{k}}$ situation the criterion is (from Eqs. 6 \& 14):

$$
\varepsilon>0.389\left(\frac{v_{1}^{3}}{r_{1}}\right)
$$

In both cases, we find that turbulence is most significant for slow-swimming predators (low $v_{1}$ ) with long reactive distances (high $r_{1}$ ), and for predators with reactive distances exceeding the Kolmogorov scale. As an example, consider a $1.2 \mathrm{~cm}$ herring larva with a 
reactive distance of $1.5 \mathrm{~cm}$ (i.e. $d>L_{\mathrm{k}}$ ) and a swimming velocity of $1 \mathrm{~cm} \mathrm{~s}^{-1}$ (Munk \& Kiørboe 1985). For this situation, Eq. (17) means that $\varepsilon$ must be $>0.25 \mathrm{~cm}^{2} \mathrm{~s}^{-3}$ for turbulence to dominate in influencing prey encounter. We conclude that turbulence is important only in highly energetic environments, such as tidal fronts, where recently hatched herring larvae in fact appear to occur frequently (Iles \& Sinclair 1982, Kiørboe et al. 1988). More generally, larval fish swimming velocities and reactive distances appear to increase approximately proportionally to body length (Blaxter 1986). Eq. (17) therefore implies that the turbulence required to affect larval feeding increases with the length of the larva raised to the power of ca 2. In other words, the significance of turbulence in enhancing prey encounter rates declines rapidly with size and is, thus, insignificant for larval fish larger than a few $\mathrm{cm}$ in length.

For swimming predators operating below the Kolmogorov scale (e.g. protozoans) turbulence is also unimportant because viscosity dampens fluid motion. For example, for a $25 \mu \mathrm{m}$ diameter Strombidium-type ciliate with a swimming velocity of $0.01 \mathrm{~cm} \mathrm{~s}^{-1}$ (Jonsson 1989). Eq. (16) yields $\varepsilon>3.6 \mathrm{~cm}^{2} \mathrm{~s}^{-3}$ (note: $r_{1}=$ diameter of ciliate), a dissipation rate unlikely to occur in the ocean (Table 1). Non-motile protozoan predators, like heliozoans and foraminiferans, however, may benefit from or even depend on ambient fluid motion for prey encounter (Shimeta \& Jumars 1991).

\section{Case 2: Sinking (ambush predators) and feeding currents (suspension feeders)}

The equations are exactly the same as for straight swimming, except that $v_{1}$ should be replaced by predator sinking velocity and prey velocity (in the feeding current, relative to the predator), respectively, in Eqs. (16) \& (17). The ambush-feeding copepod Acartia tonsa provides an example. With the reaction distance and sinking velocity provided by Jonsson \& Tiselius (1990) for this copepod $10.1 \mathrm{~cm}$ and $0.069 \mathrm{~cm} \mathrm{~s}^{-1}$ respectively), Eq. (17) yields $\varepsilon>10^{-3} \mathrm{~cm}^{2} \mathrm{~s}^{-3}$. Thus, turbulence dominates prey encounter in the neritic habitats occupied by $A$. tonsa (see further discussion below and Table 1)

\section{Case 3: Random walk}

For $d<L_{\mathrm{k}}$ we get:

$$
\varepsilon>0.91\left(\frac{D_{1}^{2}}{r_{1}^{4}}\right)
$$

and for $d>L_{\mathrm{k}}$

$$
\varepsilon>25\left(\frac{D_{1}^{3}}{r_{1}{ }^{4}}\right)
$$

The general result here is as above; turbulence is most important for predators with low motility and large reaction distances above the Kolmogorov scale. Overall, this analysis suggests that turbulence is unimportant for very large and for most very small predators, being potentially significant only for meso-sized predators operating around the Kolmogorov length scale.

\section{COPEPOD FEEDING IN CALM AND TURBULENT ENVIRONMENTS}

Copepods have different feeding modes and may thus serve as examples of several different predatory behaviours. In the following we shall apply the encounter rate models to the feeding behaviour of a few representative copepods.

\section{Copepods as ambush predators: Acartia tonsa}

When feeding on ciliates the copepod Acartia tonsa behaves as an ambush predator: it hangs quietly in the water while slowly sinking, scanning for potential approaching prey. Jonsson \& Tiselius (1990) give a detailed description of this behaviour. Ciliate prey are perceived by means of antennae (which extend ca $1 \mathrm{~mm}$ from the body proper), which carry hairs sensitive to hydromechanical stimuli. Every ca $1 \mathrm{~s}$ the copepod jumps upwards into a new parcel of water. Once a ciliate has been perceived, the copepod reorients itself towards the prey, jumps towards it and (attempts to) catch the ciliate. This sequence of events takes on the order of $0.1 \mathrm{~s}$. Other copepods show predatory behaviour similar to that described here for A. tonsa, e.g. Acartia clausi, Centropages hamatus and Centropages typicus (Tiselius \& Jonsson 1990), none of which is restricted to ambush predation. Most oithonid copepods appear to be almost obligate ambush predators (e.g. Paffenhöfer 1993).

Saiz \& Kiørboe (1995, this issue) reported clearance rates of Acartia tonsa feeding on the ciliate Strombidium sulcatum (diameter ca $30 \mu \mathrm{m}$ ) at low, unsaturating concentrations in both calm and turbulent environments. They found maximum clearance rates of ca 200 $\mathrm{ml}$ copepod $\mathrm{d}^{-1} \mathrm{~d}^{-1}$ in calm water and ca $700 \mathrm{ml}$ cope$\operatorname{pod}^{-1} \mathrm{~d}^{-1}$ in turbulent water with $\varepsilon=2.3 \times 10^{-2} \mathrm{~cm}^{2} \mathrm{~s}^{-3}$. How do these observations compare to our model?

The behavioural kernel can be approximated using different assumptions, i.e. either as a random walk for 
both prey and predator, or sinking of the predator and a random walk of the prey. Neither is entirely correct, because the predator does not sink all the time, and the 'tumbles' (i.e. jumps) of the predator do not give rise to swimming in a new, random direction. For the sake of this exercise we shall compare the kernels for both behavioural types.

If we assume a random walk, then the diffusion coefficient of the predator, $D_{1}$, can be estimated as (Eq. 8) $1.59 \times 10^{-3} \mathrm{~cm}^{2} \mathrm{~s}^{-1}$ for Acartia tonsa. Fenchel \& Jonsson (1988) found that the motility $\left(D_{2}\right)$ of the ciliate prey (Strombidium sulcatum) varied considerably with its nutritional state. Starved ciliates have higher motility than well-fed ones, an adaptation to find and remain in patches of food, respectively. Values ranged between $10^{-5} \mathrm{~cm}^{2} \mathrm{~s}^{-1}$ for well-fed ciliates up to $10^{-2}$ $\mathrm{cm}^{2} \mathrm{~s}^{-1}$ for the long-starved ones. For the growing ciliates in the experiments of Saiz \& Kiørboe (1995) a diffusion coefficient of $D_{2}=10^{-4} \mathrm{~cm}^{2} \mathrm{~s}^{-1}$ can be estimated (Fenchel \& Jonsson 1988). We further assume that $A$. tonsa has a spherical perceptive volume with $r_{1}=$ $0.1 \mathrm{~cm}$. With prey radius $r_{2}=15 \times 10^{-4} \mathrm{~cm}$, the behaviourai kernel becomes (random waik, Eq. 9) $\beta_{\text {behavrour }}=$ $186 \mathrm{ml} \mathrm{d}^{-1}$, which is close to the observed calm-water clearance rate of ca $200 \mathrm{ml} \mathrm{d}^{-1}$

The contribution of ciliate motility to prey encounter in this calculation is negligible; assuming $D_{2}=0$ yields $\beta_{\text {behaviour }}=175 \mathrm{ml} \mathrm{d}^{-1}$. However, copepods may encounter starving and highly motile ciliates at a considerably higher rate; assuming $D_{2}=10^{-2} \mathrm{~cm}^{2} \mathrm{~s}^{-1}$ yields $\beta_{\text {behaviour }}=1277 \mathrm{ml} \mathrm{d}^{-1}$. This demonstrates the high predation risk that starving ciliates may experience when searching for food patches.

An alternative - and perhaps more appropriate approach is to model prey encounter during ambush predation as differential settling. Assuming a copepod settling velocity of $0.069 \mathrm{~cm} \mathrm{~s}^{-1}$, and ignoring the motility and sinking of the ciliate (which are both negligible for growing ciliates), we estimate (Eq. 10) $\beta_{\text {behaviour }}=193 \mathrm{ml} \mathrm{d}^{-1}$, which is very similar to the above estimate (but, as expected, slightly higher because, by assuming differential settling, we assume that the copepod never meets the same volume of water twice).

To calculate the kernel for turbulence, $\beta_{\text {turbulence, we }}$ apply the $d>L_{k}$ equation, because at a dissipation rate of $2.3 \times 10^{-2} \mathrm{~cm}^{2} \mathrm{~s}^{-3}$, the reaction distance $(0.1 \mathrm{~cm})$ is close to the Kolmogorov length scale $(0.08 \mathrm{~cm})$. Thus, from Eq. (14) $\beta_{\text {turbulence }}=508 \mathrm{ml} \mathrm{d}^{-1}$. Then, the total kernel, $\beta=\beta_{\text {behaviour }}+\beta_{\text {turbulence }}$ is $694 \mathrm{ml} \mathrm{d}^{-1}$ for the diffusion model, and $701 \mathrm{ml} \mathrm{d}^{-1}$ for the differential settling model.

The main conclusion here is that turbulence has a substantial effect on prey encounter rate in ambushfeeding Acartia tonsa and likely other copepods with similar behaviours. The similarity between predicted and observed clearance rates suggests that the model predicts clearance rates of $A$. tonsa on ciliates reasonably well, in both calm and turbulent conditions. It also suggests that neither the capture success nor the reactive distance is significantly influenced by this magnitude of water motion.

\section{Copepods with feeding currents: Eucalanus spp. and others}

As noted above, many copepods generate feeding currents to enhance velocity differences and, hence, encounter rates between themselves and their algal prey (e.g. diatoms). Paffenhöfer \& Lewis (1990) presented a detailed study of clearance rates, feeding current velocities and perceptive distances for the copepod Eucalanus pileatus feeding on diatom cells (Thalassiosira weissflogii, diameter ca $12 \mu \mathrm{m}$ ); Strickler (1982, 1985) provided further information on the related species Eucalanus crassus. We combined (but simplified this information for use as an example here. The feeding current is generated by the motion of some of the feeding appendages, while food particles are gathered by others, mainly the maxillipeds. Only cells suspended in the water passing through the capture volume (i.e. the volume swept or covered by the maxillipeds) can be collected. Strickler (1982, 1985) estimated that for $E$. crassus the fluid velocity at the entrance of the capture volume is $\leq 1 \mathrm{~cm} \mathrm{~s}^{-1}$, and that the cross-sectional area of the capture volume is $0.005 \mathrm{~cm}^{2}$, equivalent to a capture radius $\left(r_{1}\right)$ of $0.04 \mathrm{~cm}$

If the copepod were unable to sense the diatoms individually, the behavioural kernel (= calm-water clearance rate) would be (Eq. 11) $447 \mathrm{~cm}^{3} \mathrm{~d}^{-1}$. At a dissipation rate of, say, $10^{-2} \mathrm{~cm}^{2} \mathrm{~s}^{-1}$ (equivalent to a shear rate of $1 \mathrm{~s}^{-1}$ ) the kernel for below-Kolmogorov scale turbulence $\left(L_{\mathrm{k}}=0.1 \mathrm{~cm}>r_{1}=0.04 \mathrm{~cm}\right)$ is $(\mathrm{Eq} .13) 8 \mathrm{~cm}^{3}$ $\mathrm{d}^{-1}$. Even if we apply the $>$ Kolmogorov scale equation (Eq. 14), which may be warranted (Hill et al. 1992), we get $\beta_{\text {turbulance }}=45 \mathrm{~cm}^{3} \mathrm{~d}^{-1}$. That is, there is at most a $10 \%$ increase in clearance rate due to this intensity of turbulence.

However, Eucalanus spp. can perceive cells individually and reroute particles from the 'sensory core' into the 'viscous core' (basically by changing the direction of the viscous core $e_{i}$ Fig. 1). For example, $E$. pileatus can perceive Thalassiosira weissflogii cells at a distance of about $0.05 \mathrm{~cm}$ (on average) from the tip of the maxilliped. The total reaction distance can be approximated by the sum of the length of the maxilliped and the perceptive distance $(=0.14 \mathrm{~cm})$. At this distance from the copepod the current velocity is $\mathrm{ca} 0.4 \mathrm{~cm} \mathrm{~s}^{-1}$ 
(Paffenhöfer \& Lewis 1990, their Figs. 7 \& 8). $\beta_{\text {behaviour }}$ then becomes $2146 \mathrm{~cm}^{3} \mathrm{~d}^{-1}$ (from Eq. 11). Taking into account the fact that $E$. pileatus feeds for only $91 \%$ of the time, this estimate is not too different from the clearance rate actually measured $\left(1720 \mathrm{~cm}^{3} \mathrm{~d}^{-1}\right)$ on cells that are presumably captured with $100 \%$ efficiency (Rhizosolenia alata; Paffenhöfer \& Lewis 1990). At a dissipation rate of $\varepsilon=10^{-2} \mathrm{~cm}^{2} \mathrm{~s}^{-3}, L_{\mathrm{k}}=0.1 \mathrm{~cm}<$ $r_{1}$, we apply the $>L_{k}$ equation to obtain a $\beta_{\text {turbulence }}=$ $824 \mathrm{~cm}^{3} \mathrm{~d}^{-1}$, which is a nearly $30 \%$ increase in encounter rate above the calm-water value.

Diatom cells larger than Thalassiosira weissflogii may be perceived by Eucalanus pileatus at greater distances. This would not increase the calm-water encounter rate, because fluid velocity declines with distance from the copepod, but it will enhance the capture efficiency (see Paffenhöfer \& Lewis 1990). In addition, it would increase the relative contribution of $\beta_{\text {turbulence, both because the relevant fluid velocity is }}$ lower, and because the perceptive distance is higher (cf. Eq. 17).

The conclusion from this exercise is that turbulence has only moderate positive effects on prey encounter rates in copepods that set up feeding currents, unless they have perceptive distances much higher than in the example above (which to our knowledge are not reported in the literature). If the copepod is unable to reroute perceived phytoplankton cells, however, the effect is negligible.

We have no data to support the postulated turbulentwater clearance rates for Eucalanus spp., but we do have observations of Acartia tonsa suspension feeding rates and Centropages hamatus encounter rates in turbulent environments. When feeding on small phytoplankton cells, $A$. tonsa also generates a feeding current and strains particles by means of the maxillipeds (Paffenhöfer \& Stearns 1988, Saiz 1994). A. tonsa is believed to be unable to sense phytoplankton cells individually and to reroute them (Paffenhöfer \& Stearns 1988), and we would thus expect the effect of turbulence on feeding rates to be small, and much smaller than the effect on $A$. tonsa in ambush-feeding mode. Saiz et al. (1992) and Saiz \& Kiørboe (1995) reported either a relatively small (on average $26 \%$; unquantified intensity of turbulence) or no measurable enhancement (at dissipation rates of $10^{-2} \mathrm{~cm}^{2} \mathrm{~s}^{-3}$ ) of $A$. tonsa feeding rates, respectively.

Costello et al. (1990) and Marrasé et al. (1990) directly measured the increase in encounter rate due to turbulence $\left(\varepsilon=0.05\right.$ to $\left.0.15 \mathrm{~cm}^{2} \mathrm{~s}^{-1}\right)$ by video-recording tethered Centropages hamatus in the laboratory. At a concentration of 70 Gymnodinium spp. cells $\mathrm{ml}^{-1}$, the 'effective encounter rates' (i.e. only including encounters occurring during suspension feeding) were on average $0.33( \pm \mathrm{SD}=0.17)$ and $1.09( \pm 0.31)$ encoun- ters $\mathrm{s}^{-1}$ in calm and turbulent water respectively icalculated from Marrasé et al. 1990, their Fig. 4c). Since the copepods were suspension feeding for, respectively, 31.4 and $54.4 \%$ of the time in calm and turbulent water (Costello et al. 1990), this translates to encounter rates during suspension feeding of 1.05 and $2.0 \mathrm{~s}^{-1}$. The effective encounter radius (reaction distance, $r_{1}$ ) was considered to be $0.135 \mathrm{~cm}$ (Marrasé et al. 1990, their Fig. 2). At this distance the flow velocity is approximately $0.2 \mathrm{~cm} \mathrm{~s}^{-1}$ (Tiselius \& Jonsson 1990). The encounter rate predicted by the model in calm water (Eq. 11) is $0.82 \mathrm{~s}^{-1}$ and in turbulent water (Eqs. $11 \& 14,>L_{k}$ ) 1.7 to $2.4 \mathrm{~s}^{-1}$ (at $\varepsilon=0.05$ to $0.15 \mathrm{~cm}^{2}$ $\mathrm{s}^{-1}$ ), which fits reasonably well with the observations. The motility of the dinoflagellate prey does not add much to the encounter rate. Even when assuming a swimming velocity of $0.1 \mathrm{~cm} \mathrm{~s}^{-1}$, which has been reported for Gymnodinium nelsoni (Saiz \& Alcaraz 1992), the encounter rate in both calm and turbulent water increases by only $0.07 \mathrm{~s}^{-1}$. It explains, however, the high calm-water encounter rate observed in the control volumes, ca $0.40 \mathrm{~s}^{-1}$, which is similar to the prediction, also $0.40 \mathrm{~s}^{-1}$.

One additional potential effect of turbulence on prey encounter in suspension-feeding copepods needs to be briefly mentioned: a suspension-feeding copepod may leave a path behind itself that is depleted of food particles. Turbulence may advect this depleted water mass into the feeding current and lead to lower particle encounter rate. We suspect that this process is not particularly important because copepod swimming velocities typically exceed ambient fluid velocities and/or because copepods jump frequently into new parcels of water.

\section{TURBULENCE AND BEHAVIOUR: FEEDING CURRENTS, PREY PERCEPTION AND CAPTURE SUCCESS}

We have so far ignored the possibility that turbulence has other effects than enhancing encounter rates. We know from laboratory observations that both copepods (Costello et al. 1990, Saiz \& Alcaraz 1992, Hwang et al. 1994, Saiz 1994) and fish larvae (MacKenzie \& Kiørboe in press) may modify their behaviour in response to turbulent fluid motion, and that prey perception, feeding currents and capture success may all be influenced by turbulence as well. This may affect both the encounter rate per se and the prey ingestion rate ( $=$ encounter rate $\times$ capture success). In the following we shall briefly discuss the potential impact of turbulence on copepod feeding currents, on prey perception, and on capture (pursuit) success. 


\section{Feeding currents}

The velocity of the copepod feeding current $(v)$ declines as an inverse power function of the distance $(r)$ to the copepod (Yen et al. 1991); i.e. $v=a r^{-b}$. The shear rate, $\gamma=|\partial v / \partial r|$, then varies as a function of the distance as $\gamma=a b r^{-\{b+1)}$. The pertinent question is whether the fluid shear rate due to oceanic turbulence is sufficiently strong to erode the shear field generated by the copepod at a distance related to the reaction distance. From the detailed flow fields depicted in Paffenhöfer \& Lewis (1990) for Eucalanus pileatus we calculated $v=0.0167 r^{-1.63}$ for the flow field in front of the copepod $\left(\mathrm{r}^{2}=0.98\right)$, where $v$ is expressed in $\mathrm{cm} \mathrm{s}^{-1}$ and $r$ in $\mathrm{cm}$. Thus, the shear rate declines as $\gamma=0.0273 r^{-2.63}$, and the shear rate at 1 reaction distance $(0.14 \mathrm{~cm}$ for Thalassiosira weissflogii, cf. above) is ca $5 \mathrm{~s}^{-1}$. Only at extreme turbulent intensities in the ocean does the environmental shear rate approach such values (Table 1), and we conclude that for $E$. pileatus turbulence does not normally affect the feeding current seriously. We made similar calculations for the flow fielus generdied by 5 neritic copepods as reported by Tiselius \& Jonsson (1990) (Table 2). We do not know the reaction distances for these copepods, but calculated the shear rate at 1 body (cephalothorax) length from the centre of the capture volume; we thus arbitrarily assume that 1 body length is an upper estimate of the perceptive distance. For $E$. pileatus (cephalothorax length

Table 2. Ventro-anterior $\left(v_{v}, \mathrm{~cm} \mathrm{~s}^{-1}\right)$ and anterior $\left(v_{a}, \mathrm{~cm} \mathrm{~s}^{-1}\right)$ feeding current velocity as a function of distance $\left(r_{1} \mathrm{~cm}\right)$ from the base of the food-collecting appendages in various copepods. Body lengths (cephalothorax, $\mathrm{cm}$ ) and shear rates $\left(\gamma_{\mathrm{v}}\right.$ and $\gamma_{a}, s^{-1}$, at a distance equal to 1 body length are also shown. Based on data presented in Paffenhöfer \& Lewis (1990) (Eucalanus pileatus) and Tiselius \& Jonsson (1990) (aIl other species\}

\begin{tabular}{|c|c|c|c|}
\hline Species & $\begin{array}{c}\text { Body } \\
\text { length } \\
(\mathrm{cm})\end{array}$ & $\begin{array}{l}\text { Current } \\
\text { velocity } \\
\left(\mathrm{cm} \mathrm{s}^{-i}\right)\end{array}$ & $\begin{array}{c}\text { Shear at } 1 \\
\text { body length } \\
\left(\mathrm{s}^{-1}\right)\end{array}$ \\
\hline $\begin{array}{c}\text { Paracalanus } \\
\text { parvus }\end{array}$ & 0.067 & $\begin{array}{l}v_{a}=0.096 r^{-0.38} \\
v_{v}=0.054 r^{-0.51}\end{array}$ & $\begin{array}{l}\gamma_{a}=1.5 \\
\gamma_{v}=1.6\end{array}$ \\
\hline $\begin{array}{l}\text { Pseudocalanus } \\
\text { elongatus }\end{array}$ & 0.092 & $\begin{array}{l}v_{\bar{d}}=0.026 r^{-0.80} \\
v_{1}=0.007 I^{-1.12}\end{array}$ & $\begin{array}{l}\gamma_{d}=1.6 \\
\gamma_{v}=1.3\end{array}$ \\
\hline $\begin{array}{l}\text { Temora } \\
\text { longicornis }\end{array}$ & 0.092 & $\begin{array}{l}v_{\mathrm{a}}=0.004 r^{-1.67} \\
v_{\mathrm{v}}=0.006 r^{-1.62}\end{array}$ & $\begin{array}{l}\gamma_{a}=3.1 \\
\gamma_{v}=4.3\end{array}$ \\
\hline $\begin{array}{l}\text { Centropages } \\
\text { typicus }\end{array}$ & 0.127 & $\begin{array}{l}v_{\mathrm{d}}=0.051 r^{-0.38} \\
v_{\mathrm{v}}=0.028 r^{-0.51}\end{array}$ & $\begin{array}{l}\gamma_{a}=1.5 \\
\gamma_{\nu}=2.2\end{array}$ \\
\hline $\begin{array}{c}\text { Centropages } \\
\text { hamafus }\end{array}$ & 0.103 & $\begin{array}{l}v_{a}=0.103 r^{-0.38} \\
v_{v}=0.299 r^{-0.51}\end{array}$ & $\begin{array}{l}\gamma_{d}=4.1 \\
\gamma_{v}=2.7\end{array}$ \\
\hline $\begin{array}{l}\text { Eucalanus } \\
\text { pileatus }\end{array}$ & 0.2 & $v=0.017 r^{-038}$ & $\gamma=1.9$ \\
\hline
\end{tabular}

ca $0.2 \mathrm{~cm}$ ) the shear rate at 1 body length distance is $1.9 \mathrm{~s}^{-1}$; for the 5 species it varies between 1.5 and $4.0 \mathrm{~s}^{-1}$ (Table 2). Thus, it seems that typical and even. relatively high intensities of ocean turbulence have limited influence on the feeding currents generated by copepods.

\section{Prey perception}

Most algal cells are perceived by copepods by means of chemoreception (see review by Price 1988). In the shear field of the feeding current, exudates released by the phytoplankton cell will reach the copepod prior to arrival of the cell itself (Strickler 1985). Because the chemical signal has to follow the flow lines, it will be disturbed by turbulence only if the shear field generated by the feeding current is disturbed. As noted above, this is unlikely to be relevant at most natural intensities of ocean turbulence.

The hydromechanical signal generated by moving prey may be disturbed by turbulence. The 'noise' generated by iubulence may decrease the signal-to-noise ratio which would translate into a decrease in the perception distance of the predator. Copepods perceive the fluid deformation rate generated by a moving prey by mechanosensitive setae on the 1st antennae (Haury et al. 1980, Landry 1980, Gill \& Crisp 1985). The setae on the first antennae act as medium-vibration sensors (Tautz 1979). The signal (S) generated by a swimming prey decays with the inverse of the distance squared (Tautz 1979); thus,

$$
S_{r}=\frac{S_{0}}{r^{2}}
$$

where $S_{r}$ and $S_{0}$ are the signal strengths at distances $r$ and 0 from the ciliate. Assume now that the signal to noise $(N)$ ratio has to exceed some critical value $\left(K_{c}\right)$ to be perceived by the copepod. The reaction distance will then be the distance at which $S / N=K_{\mathrm{c}}$. Assume next that the noise generated by turbulence is proportional to the dissipation rate:

$$
N_{\varepsilon}=a+b \varepsilon
$$

where $a$ is the background noise in calm water. By inserting the expressions for $N_{\varepsilon}$ and $S_{r}$ in $K_{c}=S / N$ and solving for $r$ we find that the reactive distance in calm water is:

$$
r_{0}=\left(\frac{a K_{c}}{S_{0}}\right)^{-0.5}
$$

and in turbulent water:

$$
r_{\varepsilon}=\left(\frac{1}{r_{0}^{2}}+\frac{b \varepsilon K_{c}}{S_{0}}\right)^{-0.5}
$$


It is difficult to obtain estimates of the involved constants. However, Saiz \& Kiørboe (1995) obtained empirical estimates of reactive distances for Acartia tonsa at various turbulent intensities. Because the observed relationship between reactive distance and $\varepsilon$ had the form predicted by Eq. (23), they concluded that turbulence affects reactive distance as suggested by this model. However, effects were only evident at turbulent dissipation rates $\left(\varepsilon>10^{-1} \mathrm{~cm}^{2} \mathrm{~s}^{-3}\right)$ higher than those commonly encountered in the ocean.

\section{Capture efficiency}

Capture efficiency of the predator may be affected by turbulence, because encountered prey may be advected out of the predator's perceptive volume before the predator reacts to it (e.g. Granata \& Dickey 1991). This may be particularly important for predators with a large perceptive sphere (long perceptive distance) and with long reaction times. Mackenzie et al. (1994) examined this theoretically; they calculated the likelihood that encountered prey would be advected out of the perceptive volume before capture, and termed this pursuit-success. We provide here a modification of Mackenzie et al.'s likelihood equation where instead of assuming that the turbulent velocity relative to the predator is constant within the reaction sphere, we assume that it declines with decreasing distance (cf. Eq. 3). The basic concepts are detailed in MacKenzie et al. (1994). Here we provide only details in the modifications performed. MacKenzie et al. (1994) showed that the probability of successful pursuit (PSP) of a prey particle at distance $d$ (< reaction distance) from the predator is given by:

$$
P S P=\frac{1}{2}\left(\rho^{3}+1-\alpha\right)+\frac{1}{4}\left(\alpha^{3}-\alpha\right)-\frac{3}{16} \frac{\left(\rho^{2}-1+\alpha^{2}\right)^{2}}{\alpha}
$$

where

$$
\alpha=\frac{d}{\omega t} \quad \text { (25), and } \quad p=\frac{r}{\omega t}
$$

and $r$ is the reaction distance, $t$ is the reaction time, and $\omega$, the turbulent velocity, is given by Eq. (3).

The expected capture success $(\delta)$ is:

$$
\delta=\frac{1}{r}\left[\int_{0}^{r-\omega t} 1 \partial d+\int_{r-\omega t}^{b \leq r} P S P(d) \partial d\right]
$$

where $b \leq r$ is the distance beyond which encountered prey is always advected away prior to capture.

Fig. 2 shows the predicted capture success at different turbulent intensities for 3 representative planktonic predators: ambush-feeding Acartia tonsa, herring larvae and cod larvae. At typical intensities of turbulence in the oceans the effect of turbulence on capture success is negligible except for predators with long pursuit (reaction) times such as cod larvae. Ambush feeding copepods, e.g. A. tonsa, and other predators, e.g. herring larvae, seem to be well adapted to turbulent environments, with detrimental effects on capture success only occurring at very high turbulent intensities $\left(\varepsilon>10^{-1} \mathrm{~cm}^{2} \mathrm{~s}^{-3}\right)$ rarely found in their environment.

\section{Prey behaviour}

So far we have considered only the effects of turbulence on the predator. As for predators, turbulence may reduce the ability of prey organisms to detect potential predators and hence to escape in advance. That would lead to an increase in capture success and higher clearance rates for the predator. An example of this effect was given by Singarajah (1975), who reported that the ability of different zooplankters to escape from a sucking siphon could be affected by stirring the water. Saiz \& Alcaraz (1992) reported an increase in the number of escape responses (long jumps) in response to turbulence in the copepod Acartia clausi. This increase in escape responses could contribute either to enhancing contact rates or to making it more difficult for a potential predator to attempt an attack. However, this may be of little relevance at rep-



Fig. 2. Decline in capture success as a function of turbulence intensity for 3 representative predators. Capture success has been estimated from a modified version of the model by Mackenzie et al. (1994). The predators are: Acartia tonsa feeding on ciliates (ambush predatory behaviour; reaction distance: $0.1 \mathrm{~cm}$; reaction time: $0.1 \mathrm{~s}_{\mathrm{i}}$ Jonsson \& Tiselius 1990); herring larvae (reaction distance: $1.5 \mathrm{~cm}$; reaction time: $1 \mathrm{~s}$; Munk \& Kiørboe 1985) and cod larvae (reaction distance: $0.6 \mathrm{~cm}$; reaction time: $1.7 \mathrm{~s}$; MacKenzie et al. 1994) 
resentative turbulent intensities. Tiselius \& Jonsson (1990) and Yen \& Fields (1992) reported that escape responses in copepod nauplii were initiated at shear rates above 0.8 to $2 \mathrm{~s}^{-1}$. Similarly, Kirk \& Gilbert (1988) reported that the escape response of rotifer Polyarthra remata was triggered by shear values of 1 to $3 \mathrm{~s}^{-1}$. Such high shear rates are found only in highly energetic environments (see Table 1). Obviously the behavioural response of the potential prey to turbulence will determine the importance of prey behaviour when estimating the kernels due to turbulence.

\section{CONCLUSIONS}

The effect of turbulence on prey encounter rates in planktivorous predators depends strongly on the feeding behaviour of the predator, on the motility of both predator and prey, and on the scales at which the predator operates. Prey encounter rates depend on velocity differences between prey and predator. Those predators that, due to their behaviour, generate only sindil velocity differences are most affected by turbulent fluid motion. We have provided simple models that allow us to describe encounter rates between predator and prey, and to predict which behaviours are most affected by turbulence. Generally, turbulence is potentially most important for meso-sized (mm to $\mathrm{cm}$ ) predators with perceptive distances close to the Kolmogorov length scale, and less important for smallerand larger-sized predators. Copepods that set up feeding currents are largely independent of ambient fluid velocity for prey encounters, while ambush-preying copepods benefit substantially. Entangling ambush predators such as many medusae, siphonophores and ctenophores, which have large encounter zones and rely heavily on the movement of the prey (Madin 1988), are also potentially favoured by turbulence. Cruising predators, like many fish larvae, occupy an intermediate position, and benefit from turbulent fluid motion only at relatively high turbulent intensities. Negative effects of turbulence on feeding currents, prey perception and capture success are unimportant for most predators at realistic intensities of ocean turbulence.

Empirical data on the effects of turbulence on trophic interactions are still scarce and experimental data are needed to test the models proposed here. Specifically, descriptions of feeding behaviours and observations on prey encounter and feeding rates in calm and turbulent waters for a variety of predators with different feeding behaviours (ambush and suspension feeders, cruising and pause-travel predators, etc.) are required to more fully understand the effects of turbulence on trophic interactions in the plankton.
The differential effects of turbulence on prey encounters in predators with different behaviours, as proposed in this study, may potentially lead to differences in distribution patterns of organisms relative to turbulence. We suggest that species benefiting from turbulence may be overrepresented in energetic environments while species to which turbulence is detrimental may be overrepresented in calmer environments. Recent field observations suggest, in fact, that the distribution of both copepods and fish larvae may be modified by variations in turbulent intensity (e.g. Heath et al. 1988, Haury et al. 1990) and that different species respond to turbulence differently (Mackas et al. 1993), but the underlying causalities are still incompletely understood. The models proposed here may help to interpret observed field distributions of planktonic predators with known feeding behaviours.

Acknowledgements. Wc benefited from conversations held with Brian MacKenzie, Jan Beyer, George Jackson, Per Jonsson and Peter Tiselius. This study was supported by a grant to T.K. from the Danish Natural Science Research Council (no. 11-0420-1\} and by grants CYCIT MAR91-0359. CIRIT EE9312 and CIRIT BE94-529 to E.S.

\section{LITERATURE CITED}

Berg HC (1983) Random walks in biology. Princeton University Press, Princeton

Blaxter JHS (1986) Development of sense organs and behaviour of teleost larvae with special reference to predator avoidance. Trans Am Fish Soc 115:98-114

Costello JH, Strickler JR, Marrasé C, Trager G, Zeller R, Freise AJ (1990) Grazing in a turbulent environment: behavioral response of a calanoid copepod Centropages hamatus. Proc Natl Acad Sci USA 87:1648-1652

Davis CS, Flierl GR, Wiebe PH, Franks PJS (1991) Micropatchiness turbulence and recruitment in plankton. $J$ mas Res 49:109-151

Delichatsios MA, Probstein RF (1975) Coagulation in turbulent flow: theory and experiment. J Coll Interf Sci 51: $394-405$

Evans GT (1989) The encounter speed of moving predator and prey. J Plankton Res 11:415-417

Fenchel T, Jonsson R (1988) The functional biology of Strombidium sulcatum, a marine oligotrich ciliate (Ciliophora, Oligotrichina). Mar Ecol Prog Ser 48:1-15

Gerritsen J, Strickler JR (1977) Encounter probabilities and community structure in zooplankton: a mathematical model. J Fish Res Bd Can 34:73-82

Gill CW, Crisp DJ (1985) Sensitivity of intact and antennule amputated copepods to water disturbance. Mar Ecol Prog Ser 21:221-227

Granata TC, Dickey TD (1991) The fluids mechanics of copepod feeding in a turbulent flow: a theoretical approach. Prog Oceanogr 26:243-261

Haury LR, Kenyon DE, Brooks JR (1980) Experimental evaluation of the avoidance reaction of Calanus finmarchicus. J Plankton Res 2:187-202

Haury LR, Yamazaki H, Itsweire EC (1990) Effects of turbulent shear flow on zooplankton distribution. Deep Sea Res $37: 447-461$ 
Heath MR, Henderson EW, Baird DL (1988) Vertical distribution of herring larvae in relation to physical mixing and illumination. Mar Ecol Prog Ser 47:211-228

Hill PS, Nowell ARM, Jumars PA (1992) Encounter rate by turbulent shear of particles similar in diameter to the Kolmogorov scale. J mar Res 50:643-668

Hwang JS, Costelio JH, Strickler JR (1994) Copepod grazing in turbulent flow: elevated foraging behaviour and habituation of escape responses. J Plankton Res 16:421-431

Iles TD, Sinclair M (1982) Atlantic herring: stock discreteness and abundance. Science 215:627-633

Jackson GA, Lochmann S (1993) Modeling coagulation of algae in marine ecosystems. In: Buffle J, van Leeuwen $\mathrm{HP}$ (eds) Environmental analytical and physical chemistry series, Vol 2, Environmental particles. Lewis Publishers, Boca Raton, p $387-414$

Jonsson PR (1989) Vertical distribution of planktonic ciliates - an experimental analysis of swimming behaviour. Mar Ecol Prog Ser 52:39-53

Jonsson PR, Tiselius P (1990) Feeding behaviour, prey detection and capture efficiency of the copepod Acartia tonsa feeding on planktonic ciliates. Mar Ecol Prog Ser 60:35-44

Kiorboe T (1993) Turbulence, phytoplankton cell size, and the structure of pelagic food webs. Adv mar Biol 29:1-72

Kiørboe T, Munk P, Richardson $\mathrm{K}$, Christensen V, Paulsen $\mathrm{H}$ (1988) Plankton dynamics and herring larval growth, drift and survival in a frontal area. Mar Ecol Prog Ser 44: $205-219$

Kirk KL. Gilbert JJ (1988) Escape behavior of Polyarthra in response to artificial flow stimuli. Bull mar Sci 43:551-560

Landry MR (1980) Detection of prey by Calanus pacificus: implications of the first antennae. Limnol Oceanogr 25: $545-549$

Mackas DL, Sefton H, Miller CB, Raich A (1993) Vertical habitat partitioning by large calanoid copepods in the oceanic subarctic Pacific during spring. Prog Oceanogr 32: $259-294$

MacKenzie BR, Kiorboe $T$ (in press) Encounter rates and swimming behaviour of pause-travel and cruise larval fish predators in calm and turbulent laboratory environments. Limnol Oceanogr

MacKenzie BR, Leggett WC (1991) Quantifying the contribution of small-scale turbulence to the encounter rates between larval fish and their zooplankton prey: effects of wind and tide. Mar Ecol Prog Ser 73:149-160

MacKenzie BR, Leggett WC (1993) Wind-based models for estimating the dissipation rates of turbulent energy in aquatic environments: empirical comparisons. Mar Ecol Prog Ser 94:207-216

MacKenzie BR, Miller TJ, Cyr S, Leggett WC (1994) Evidence for a dome-shaped relationship between turbulence and larval fish ingestion rates. Limnol Oceanogr 39:1790-1799

Madin LP (1988) Feeding behavior of tentaculate predators: in situ observations and a conceptual model. Bull mar Sci 43:413-429

Mann KH, Lazier JRN (1991) Dynamics of marine ecosystems. Biological-physical interactions in the oceans. Blackwell Scientific Publications, Boston

Marrasé C, Costello JH, Granata T, Strickler JR (1990) Grazing in a turbulent environment. II. Energy dissipation encounter rates and efficacy of feeding currents in Centropages hamatus. Proc Natl Acad Sci USA 87:1653-1657

Munk P, Kiørboe T (1985) Feeding behaviour and swimming activity of larval herring (Clupea harengus) in relation to density of copepod nauplii. Mar Ecol Prog Ser 24:15-21

O'Melia CR, Tiller CL (1993) Physicochemical aggregation and deposition in aquatic environments. In: Buffle J, van Leeuwen HP (eds) Environmental analytical and physical chemistry series, Vol 2, Environmental particles. Lewis Publishers, Boca Raton, p 353-386

Paffenhöfer GA (1993) On the ecology of marine cyclopoid copepods (Crustacea, Copepoda). J Plankton Res 15:37-55

Paffenhofer GA, Lewis KD (1990) Perceptive performance and feeding behavior of calanoid copepods. J Plankton Res 12:933-946

Paffenhöfer GA, Stearns DE (1988) Why is Acartia tonsa (Copepoda: Calanoida) restricted to nearshore environments? Mar Ecol Prog Ser 42:33-38

Price HJ (1988) Feeding mechanisms in marine and freshwater zooplankton. Bull mar Sci 43:327-343

Rothschild BJ, Osborn TR (1988) Small-scale turbulence and plankton contact rates. J Plankton Res 10:465-474

Saiz E (1994) Observations on the free-swimming behavior of Acartia tonsa: effects of food concentration and turbulent water motion. Limnol Oceanogr 39:1566-1578

Saiz E, Alcaraz M (1992) Free-swimming behavior of Acartia clausi (Copepoda: Calanoida) under turbulent water movement. Mar Ecol Prog Ser 80:229-236

Saiz E, Alcaraz M, Paffenhöfer GA (1992) Effects of smallscale turbulence on feeding rate and gross-growth efficiency of three Acartia species (Copepoda: Calanoida). J Plankton Res 14:1085-1097

Saiz E, Kiorboe T (1995) Predatory and suspension feeding of the copepod Acartia tonsa in turbulent environments. Mar Ecol Prog Ser 122:147-158

Shimeta J, Jumars PA (1991) Physical mechanisms and :ates of particle capture by suspension feeders. Oceanogr mar Biol A Rev 29:191-257

Singarajah KW (1975) Escape reactions of zooplankton: effects of light and turbulence. J mar biol Ass UK 55: $627-639$

Strickler JR (1982) Calanoid copepods, feeding currents, and the role of gravity. Science 218:158-160

Strickler JR (1985) Feeding currents in calanoid copepods: two new hypotheses. In: Laverack MS (ed) Physiological adaptations of marine animals. Symp Soc exp Biol 89 $459-485$

Sundby S, Fossum P (1990) Feeding conditions of Arcto-Norweglan cod larvae compared with the Rothschild-Osborn theory on small-scale turbulence and plankton contact rates. J Plankton Res 12:1153-1162

Tautz J (1979) Reception of particle oscillation in a medium an unorthodox sensory capacity. Naturwissenschaften 66 $452-461$

Tiselius P, Jonsson PR (1990) Foraging behaviour of six calanoid copepods: observations and hydrodynamic analysis. Mar Ecol Prog Ser 66:23-33

Yamazaki H. Osborn TR, Squires KD (1991) Direct numerical simulation of planktonic contact in turbulent flow. J Plankton Res 13:629-643

Yen J, Fields DM (1992) Escape responses of Acartia hudsonica (Copepoda) nauplii from the flow field of Temora longicornis (Copepoda). Arch Hydrobiol Beih Ergebn Limnol 36:123-134

Yen J, Sanderson B, Strickler JR, Okubo A (1991) Feeding currents and energy dissipation by Euchaeta rimana a subtropical pelagic copepod. Limnol Oceanogr 36: $362-369$

Manuscript first received: September 5, 1994

Revised version accepted: January 23, 1995 